\title{
Covid-19: most patients require mechanical ventilation in first 24 hours of critical care
}

\section{Elisabeth Mahase}

The BMJ

Two thirds (132) of covid-19 patients who required critical care in the UK had mechanical ventilation within 24 hours of admission, an audit of patients from England, Wales, and Northern Ireland has found.

The report from the Intensive Care National Audit and Research Centre summarised all the confirmed cases of covid-19 in critical care (199 admissions for 196 patients) up to midnight on 19 March from participating critical care units. ${ }^{1}$ Of these, $29 \%$ (57) were female and $71 \%$ (139) were male; their median age was 64.

Of the 196 patients, 16 died, 17 patients were discharged alive from critical care, and 163 patients were last reported as still being in critical care. Most of these patients (106) were being managed by the three London Operational Delivery Networks.

The audit found that 155 patients were able to live without assistance in daily activities before the onset of acute illness, 23 had previously required some assistance with daily activities, and none required total assistance with all daily activities (status of 18 patients was unknown). Of the 196 patients, 56 (32\%) had a BMI of 25 to $30,58(33 \%)$ had a BMI of 30 to 40 and $13(7 \%)$ had a BMI of 40 or higher. None were reported as pregnant at the time of admission.

In terms of medical background, 18 patients were recognised as having a severe comorbidity, such as cardiovascular symptoms at rest, or shortness of breath during routine activities, or were immunocompromised, although specific diagnoses were not detailed.

"The median length of stay in critical care was three days for both survivors and non-survivors. Of patients with a critical care outcome reported (33), 11 (33.3\%) received advanced respiratory support at any time during the critical care unit stay, $6(18.2 \%)$ received advanced cardiovascular support, and 4 $(12.1 \%)$ received renal support. The median duration of advanced respiratory support among those that received it was five calendar days," the report said.

Responding to the report, a spokesperson for the Faculty of Intensive Care Medicine said, "[The Intensive Care National Audit and Research Centre] providing rapid turnaround of data to the profession is welcomed. We know covid-19 appears to be having different impacts on different populations across the world (Germany and Italy, for example) so having a UK specific dataset will be very helpful for delivering care."

Report on 196 patients critically ill with COVID-19. ICNARC, 20 March 2020. https://www. icnarc org/About/Latest-News/2020/03/22/Report-On-196-Patients-Critically-III-With-Covid19

Published by the BMJ Publishing Group Limited. For permission to use (where not already granted under a licence) please go to http://group.bmj.com/group/rights-licensing/ permissions 